\title{
p62/IMP2 stimulates cell migration and reduces cell adhesion in breast cancer
}

\author{
Yang $\mathrm{Li}^{1}$, Giulio Francia ${ }^{1}$, Jian-Ying Zhang ${ }^{1}$ \\ ${ }^{1}$ Department of Biological Sciences \& NIH-Sponsored Border Biomedical Research Center, The University of Texas at El \\ Paso, El Paso, TX 79968, USA
}

Correspondence to:

Jian-Ying Zhang, e-mail: jzhang@utep.edu

Giulio Francia, e-mail: gfrancia@utep.edu

Keywords: breast cancer, IGF2 mRNA binding protein 2, cell migration, cell adhesion, extracellular matrix

Received: May 05, $2015 \quad$ Accepted: September 11, $2015 \quad$ Published: September 23, 2015

\section{ABSTRACT}

p62/IMP2 is an oncofetal protein that is overexpressed in several types of cancer, and is a member of the family of insulin-like growth factor $\mathbf{2}$ mRNA binding proteins. We previously reported that high levels of p62/IMP2 autoantibody are present in sera from cancer patients, compared to healthy individuals. Here, we report the overexpression of p62/IMP2 in tumor tissues of 72 out of 104 cases of human breast cancer, and high levels of p62/IMP2 autoantibody in patients' sera (in 63 out of 216 cases). To explore the role of p62/IMP2 in breast cancer progression, we generated p62/IMP2 transfected variants of two human breast cancer cell lines: MDA-MB-231 and LM2-4. Using in vitro assays we found that overexpression of p62/ IMP 2 can increase cell migration, and reduce cell adhesion to extracellular matrix (ECM) proteins. A Human Extracellular Matrix and Adhesion Molecules qPCR array was performed with our generated variants, and it identified a group of mRNAs whose expression was altered with p62/IMP2 overexpression, including connective tissue growth factor (CTGF) MRNA - which we show to be a p62/IMP2 binding partner. Overall, our results provide new insights into the molecular mechanism by which p62/IMP2 can contribute to breast cancer progression.

\section{INTRODUCTION}

The insulin like growth factor 2 mRNA-binding protein (IMP) family is a group of proteins involved in fetal development [1]. Three members (IMP1, p62/IMP2, IMP3) have been reported, and they have similar protein structures, composed of two RNA recognition motif domains and four $\mathrm{K}$ homology domains [2]. The primary function of these proteins is to bind specific mRNAs, stabilize and extend their half-life. All IMPs have been reported to be overexpressed in various cancers, including breast cancer, lung cancer, colorectal adenocarcinoma, and melanoma [3].

The IGF2 mRNA-binding protein 2 (p62/IMP2) remains the least-studied member of the IMP family [4]. p62/IMP2 is regulated by high-mobility group AT-hook 2 protein (HMGA2). HMGA2 can bind to an AT-rich region in the first intron of p62/IMP2 and regulate p62/IMP2 transcription [5]. As an mRNA-binding protein, p62/IMP2 can target different mRNAs. Among p62/IMP2 target mRNAs, most are associated with cancer progression, such as IGF2 mRNA and c-myc mRNA [3]. A number of p62/IMP2 target mRNAs have been implicated in the growth, migration, adhesion, or in the energy metabolism of cancer cells [4, 6-8].

We originally reported p62/IMP2 as a tumorassociated antigen (TAA) in hepatocellular carcinoma [9]. A high frequency of its autoantibody can be observed in several types of cancer, as we previously reported [10-12]. Aside from the presence of its autoantibody, the p62/IMP2 protein is overexpressed in several tumor types, including liposarcomas, hepatocellular carcinomas (HCC), and endometrial adenocarcinomas $[5,13,14]$. Overexpression of p62/IMP2 was also observed in some tumor cell lines (HepG2, SNU449, H1299, U2OS, HT-29, PANC-1, and IF6) [3]. However, there have been few studies on p62/ IMP2 expression in breast cancer. In contrast, IMP1, a member of the IMP family with $84 \%$ sequence similarity to p62/IMP2 [15], has been reported as being amplified (in gene copy number) in breast cancer [16]; IMP1 was also reported to be overexpressed in mammary epithelial cells of adult transgenic mice that show high incidence 
of breast cancer development [17]. In this study we evaluated whether p62/IMP2 is similarly overexpressed in breast cancer progression. We found that p62/IMP2 was overexpressed in breast tumor tissues, and high levels of its autoantibody were present in the sera of a number of patients with breast cancer, compared to healthy individuals. By transfection into breast cancer cell lines, we also found that overexpression of p62/IMP2 in breast cancer cells can increase cell migration and reduce cell adhesion.

\section{RESULTS}

\section{p62/IMP2 is overexpressed in human breast cancer tissues}

We performed immunohistochemistry (IHC) analysis of p62/IMP2 on 118 breast tissues, including 104 tumor tissues and 14 adjacent normal tissues (Table 1 shows a summary of the data obtained). High expression of p62/IMP2 was observed in human breast tumor tissues (72/104 cases, corresponding to 69\%), and low expression of p62/IMP2 was observed in the adjacent normal tissues (2/14 cases, corresponding to $14 \%$ ). Figure 1 shows 4 representative examples of p62/IMP2 staining observed using a 4-level scoring system.

p62/IMP2 has been described as a tumor-associated antigen, and a high frequency of detectable autoantibody to p62/IMP2 in sera from cancer patients has been reported. To detect the prevalence of p62/IMP2 autoantibody in sera from patients with breast cancer, recombinant p62/IMP2 protein was used as the coating antigen in an Enzymelinked immunosorbent assay (ELISA) to screen sera from breast cancer patients and from patients with benign breast lumps, as well as in sera from normal individuals. Analysis of the sera (Table 2) from 216 patients with breast cancer showed that the positive frequency of detectable p62/IMP2 autoantibody was $29 \%$ (63/216), which was significantly higher than that in sera from normal individuals $(1 \%$, $1 / 73)$, and from patients with benign lumps $(0 \%, 0 / 34)$. From the distribution of optical density (OD) value from readings of the three groups (Figure 2), it was evident that the levels in the sera from most of patients with breast cancer were above the cutoff OD value (0.32), indicating that these sera were positive for p62/IMP2 autoantibody.
In contrast, only one serum sample from a normal individual showed anti-p62/IMP2 autoantibody (OD: 0.54 ), and no sera from patients with benign breast lumps produced OD reading above the cutoff value.

\section{Overexpression of $\mathrm{p62} / \mathrm{IMP2}$ contributes to overexpression of c-myc in the MDA-MB-231 cells and LM2-4 cells}

To investigate the biological role of p62/IMP2 in breast cancer progression, we screened a panel of breast cancer cell lines and found that p62/IMP2 was expressed in the SKBr3 cell line (Figure 3A). Next we generated, by plasmid transfection, p62/IMP2 overexpressing variants of the MDA-MB-231 and LM2-4 cell lines. Two p62/IMP2 positive clones and one p62/IMP2 negative clone were chosen respectively from the two cell lines (Figure 3B and Figure 3C). Indirect immunofluorescence results confirmed the Western blotting result from the selected clones, and p62/IMP2 was found to be detectable in the cytoplasm (Figure 3D). In our p62/IMP2 overexpressing variants, we also found that c-myc protein and c-myc in mRNA level were increased compared to controls (including negative clones, and parental cells) (Figure 4), which is consistent with previous reports [7].

\section{p62/IMP2 increases cell migration and reduces cell adhesion, but does not impact cell proliferation in breast cancer cells}

To determine the impact of p62/IMP2 on breast cancer cells, the generated p62/IMP2 transfected variants were used to perform in vitro assays to evaluate relative cell adhesion, cell migration, and cell proliferation, compared to controls. The results from the wound healing assay suggested an increased migration of p62/ IMP2 positive cells compared to controls (Figure 5A). Thus, overexpression of p62/IMP2 in breast cancer cells increased 'wound' closure by $50 \%$ to $70 \%$ (Figure $5 \mathrm{~B}$ ). We also tested cell adhesion to collagen, and to fibronectin. We found that $\mathrm{p} 62 / \mathrm{IMP} 2$ positive cells were less adherent compared to control cells (Figure 5C). Thus overexpression of p62/IMP2 reduced cell adhesion by $30 \%-50 \%$ (Figure 5D). Relative cell growth was also examined using a proliferation assay, but no impact of

\section{Table 1: Expression of p62/IMP2 in breast cancer tissues and adjacent tissues}

\begin{tabular}{|l|c|c|c|c|}
\hline \multirow{nyyyy}{*}{ Type of Tissues } & Total & +++ & + & + \\
\hline Tumor Tissues (104) & $72 / 104(69 \%) *$ & $10(14 \%)$ & $23(32 \%)$ & $39(54 \%)$ \\
\hline Normal Tissues (14) & $2 / 14(14 \%)$ & $0(0 \%)$ & $1(7 \%)$ & $1(7 \%)$ \\
\hline
\end{tabular}

$* p<0.01$, compared with normal group (Fisher's exact test).

A four-level scoring system was used to evaluate the staining intensity of p62/IMP2:

$(-)=$ negative expression, $(+)=$ weak expression level, $(++)=$ moderate expression level, $(+++)=$ high expression level. 


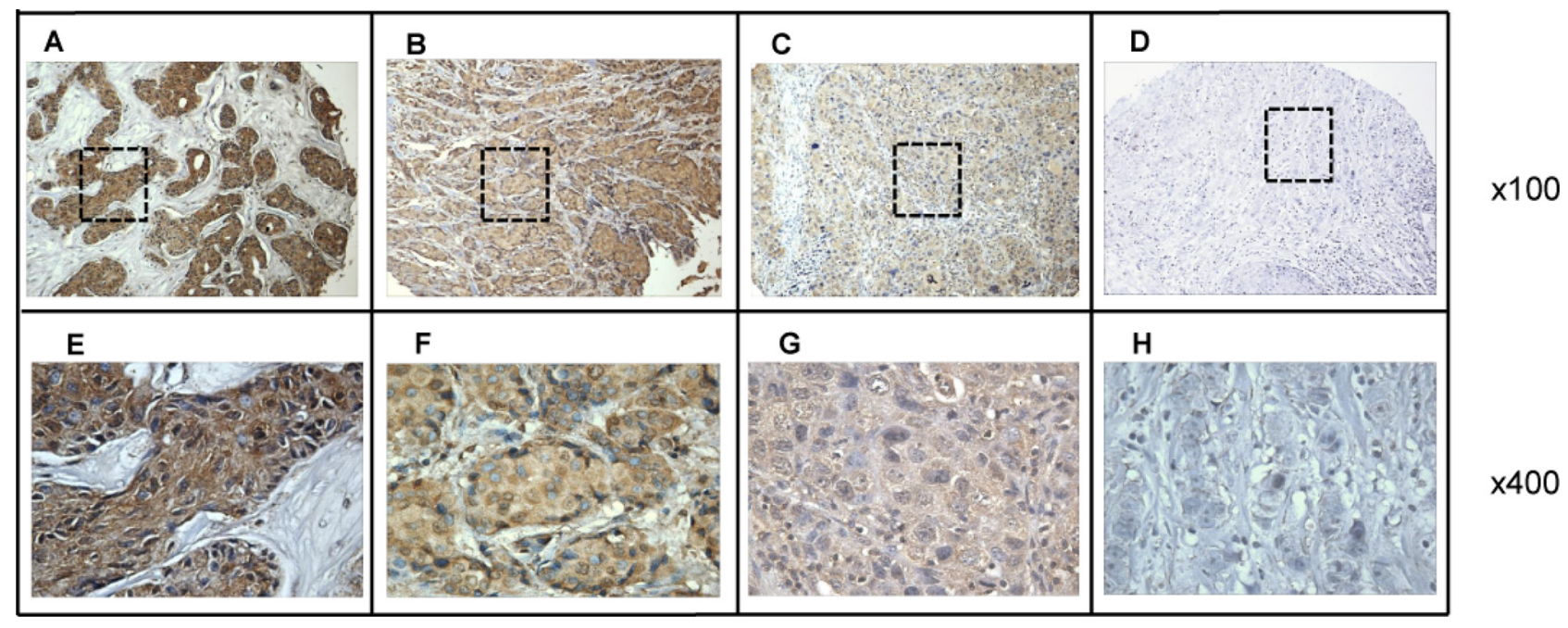

Figure 1: Immunohistochemical analysis of p62/IMP2 in four representative breast tumor tissues. A. breast tumor tissue with high expression of p62/IMP2; B. breast tumor tissue with moderate expression of p62/IMP2; C. breast tumor tissue with weak expression of p62/IMP2; D. breast tumor tissue with negative expression of p62/IMP2 (Magnification: $\times 100$ ). E, F, G. and H. The corresponding area (rectangle) of A, B, C, and D were enlarged (and presented below; magnification: $\times 400$ ). Tissue slides were stained with anti-p62/IMP2 antibody at a 1:500 dilution.

Table 2: Frequency of Autoantibody Response to p62/IMP2 Protein

\begin{tabular}{|l|c|c|}
\hline \multicolumn{1}{l}{ Group } & Total & Positive (\%) \\
\hline Breast cancer & 216 & $63(29 \%)^{* \#}$ \\
\hline Benign & 34 & $0(0 \%)$ \\
\hline Normal & 73 & $1(1 \%)$ \\
\hline Total & 323 & 64 \\
\hline
\end{tabular}

Cutoff value: Mean+3SD of normal group;

Breast cancer group vs Normal group: $* p<0.01$;

Breast cancer group vs Benign group: ${ }^{\#} p<0.01$

Breast cancer: sera from patients with breast cancer

Benign: sera from patients with breast benign lumps

Normal: sera from normal individuals

p62/IMP2 expression on breast cancer cell proliferation was observed over a 6-7 day monitoring period (Figure 5E). Taken together, these data indicate that $\mathrm{p} 62 /$ IMP2 increases cell migration and reduces cell adhesion in breast cancer cells in vitro.

\section{Selective gene expression profiling of human breast cancer cells overexpressing p62/IMP2}

To better understand how p62/IMP2 regulates cell migration and cell adhesion in breast cancer cells, a commercially available Human Extracellular Matrix \& Adhesion Molecules RT ${ }^{2}$ Profiler PCR Array was used to compare our p62/IMP2 transfectants with the p62/IMP2 negative clone cells. This array profiles the expression of 84 mRNA of genes involved in cell-cell and cell-matrix interactions. Out of 84 genes, 16 were found to be upregulated in 2-fold or greater in p62/IMP2 overexpressing cells, whereas only 2 genes were found to be downregulated (Figure 6A). At last 4 genes in this array (Table 3), including connective tissue growth factor (CTGF), versican (VCAN), ADAM metallopeptidase with thrombospondin type 1 motif, 1 (ADAMTS1), and collagen, type VII, alpha 1 (COL7A1) were confirmed, by RT-PCR, in variants from MDA-MB-231 and LM2-4 cell lines in our additional experiment (Figure 6B and Figure 6C).

\section{p62/IMP2 binds to and increases the stability of CTGF mRNA}

The CTGF protein is involved in the process of wound repair [18]. CTGF expression can be regulated by microRNAs that interact with its 3'-UTR, which results in repressed translation of CTGF or the degradation of its transcripts [19]. Previous studies have demonstrated that p62/IMP2 is an mRNA- 


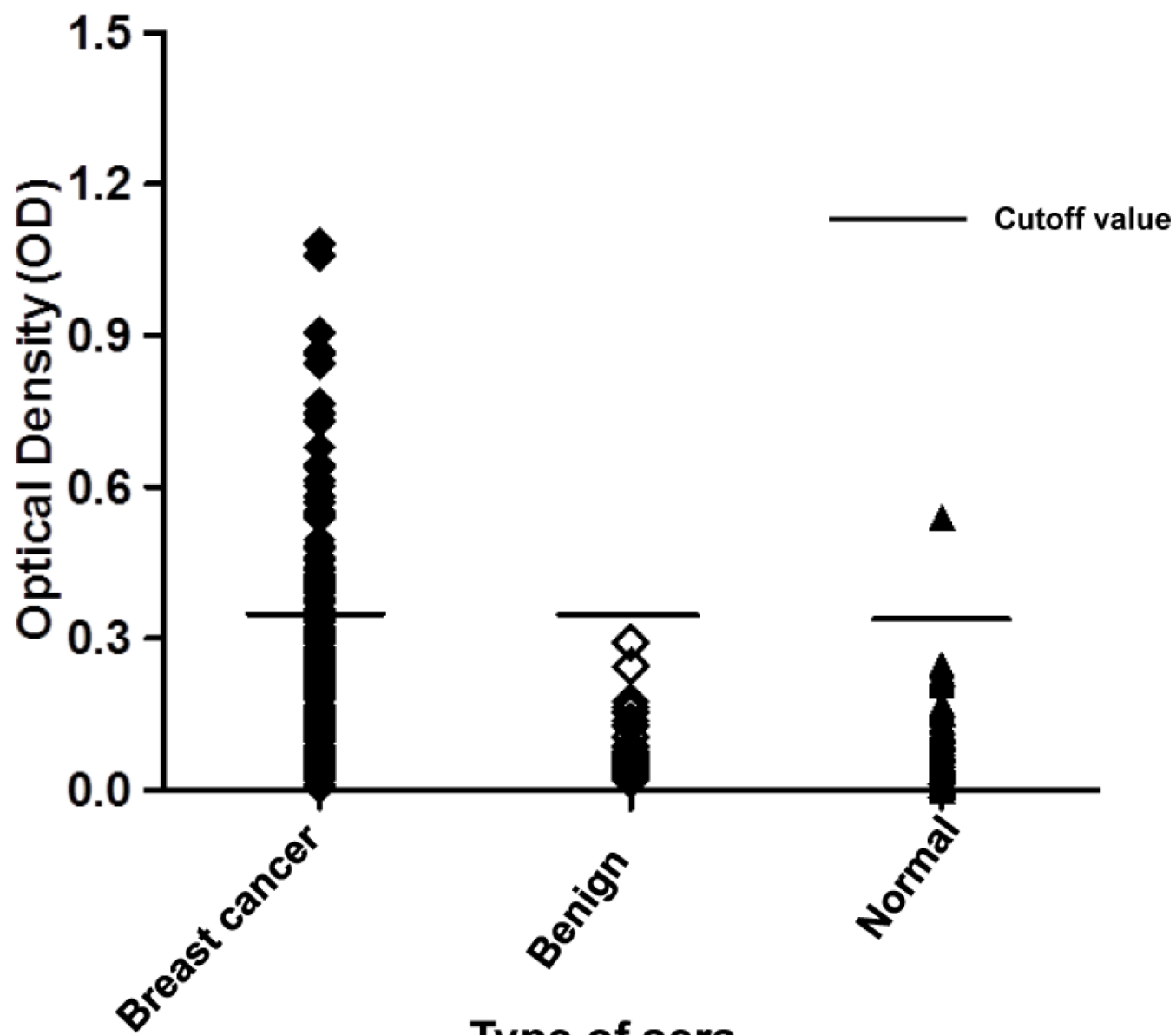

Figure 2: Titers of autoantibody against p62/IMP2 in sera from patients with breast cancer, or from individuals with benign lumps, and normal human sera. In the graph, titer of anti-p62/IMP2 autoantibody in sera from patients with breast cancer was much higher than that in the sera from individuals with benign breast lumps, and that in sera from healthy individuals. The distribution of autoantibody titers is indicated as optical density (OD) obtained from ELISA. The mean + 3SD of normal human sera are shown in relationship to all serum samples.

binding protein, which can bind its target mRNAs in the $5^{\prime}$ or $3^{\prime}$ untranslated regions (UTRs). Therefore we hypothesized that CTGF may be a novel target of p62/IMP2 in breast cancer cells. The results from Figure 7A and Figure 7B show that CTGF mRNA can be immunoprecipitated with p62/IMP2, but not with GAPDH, by using p62/IMP2 antibody. The results in Figure 7D demonstrate that this binding can stabilize the mRNA of CTGF. In clone 5 (p62/IMP2 negative) of MDA-MB-231 cells, the half-life of CTGF mRNA was $2.2 \pm 0.03$ hour. In contrast, the mRNA half-life of CTGF was increased 2.3-fold to $5.1 \pm 0.02$ hours in clone 6 (p62/IMP2 positive) of MDA-MB-231 cells $(p<0.01)$. c-myc mRNA, which is a well-studied target of p62/IMP2, was used as a positive control (Figure 7B and Figure 7C). The half-life of c-myc mRNA was $0.3 \pm 0.19$ hours in clone 5 , and the half-life of c-myc mRNA in clone 6 was $0.8 \pm 0.23$ hours $(p=0.044)$. In summary, our data indicated that p62/IMP2 can bind to and stabilize the mRNA of CTGF.

\section{DISCUSSION}

The results of this study indicate that p62/IMP2 overexpression is observed in breast cancer tissues. Furthermore, by ELISA we observed a high frequency of anti-p62/IMP2 autoantibody in sera from breast cancer patients. A previous study demonstrated that p62/IMP2 is developmentally regulated and is expressed in fetal liver tissues but not in adult livers, and yet it is also overexpressed in liver tissues from patients with HCC [13]. Detectable autoantibody to p62/IMP2 was found to be present in $21.1 \%$ of HCC patients from China but not in patients with precursor conditions such as chronic hepatitis and liver cirrhosis [9]. Liu et al. found the overexpression of p62/ IMP2 in colon cancer tissues by IHC [10]. In a study of 82 patients with digestive canal tumors, $38.6 \%$ of patients were positive for autoantibody to p62/IMP2, and $33.7 \%$ of those patients had metastatic disease, which suggests that the anti-p62/IMP2 autoantibody might be a predictive marker for cancer metastasis [20]. Overall these data indicate a 


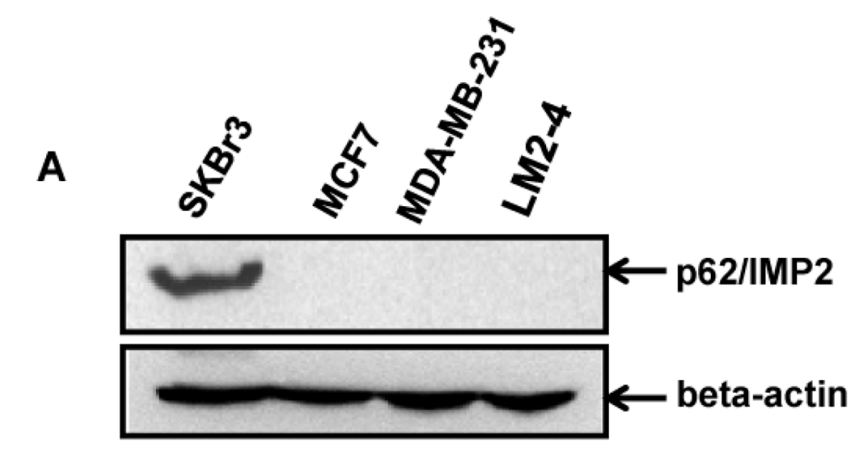

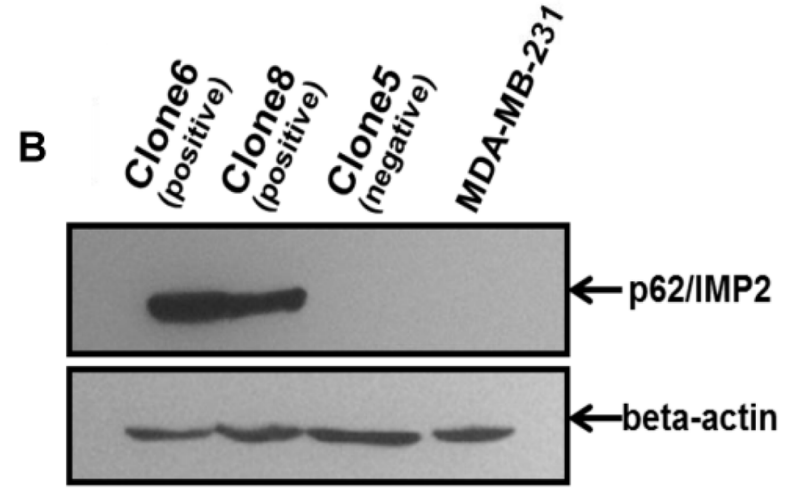

MDA-MB-231 cells

D

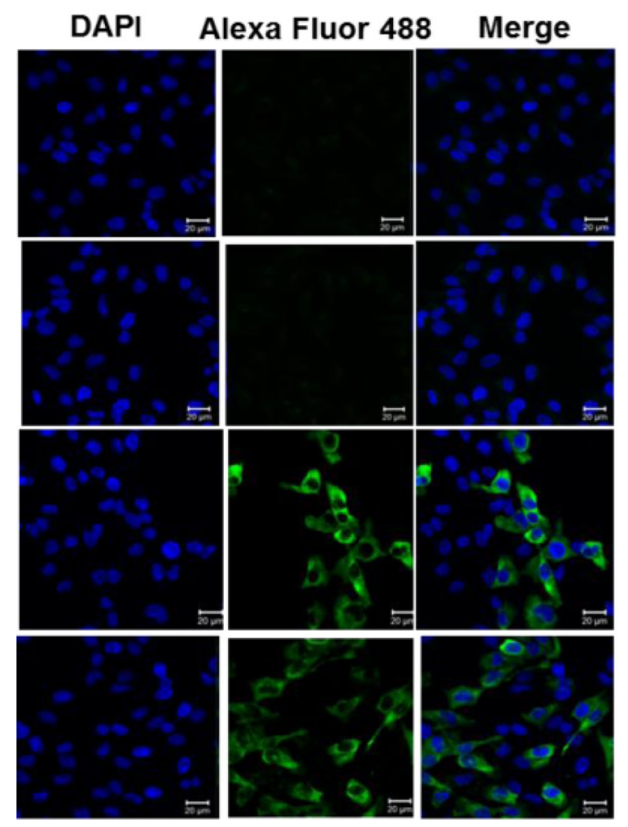

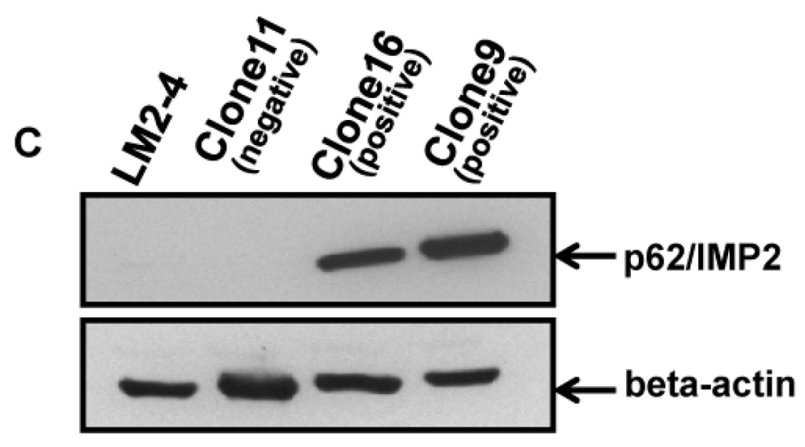

LM2-4 cells

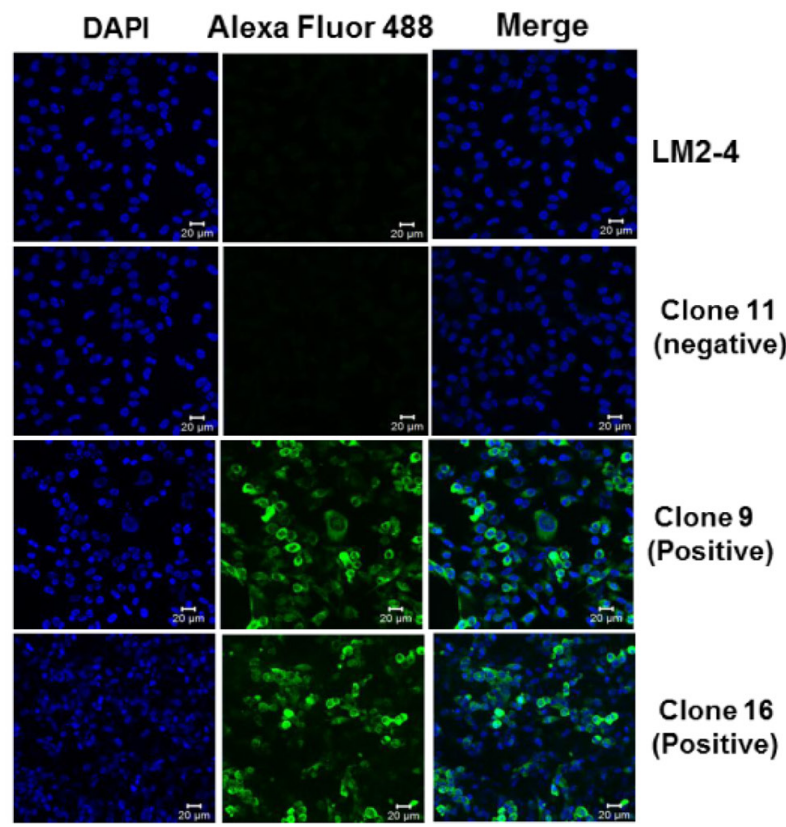

Figure 3: The generation of variants with stable overexpression of p62/IMP2 in breast cancer cells. Western blotting analysis of p62/IMP2 in four human breast cancer cell lines showed p62/IMP2 was expressed in SKBr3 cells A. Variants with stable overexpression of p62/IMP2 were generated with MDA-MB-231 cells B. and LM2-4 cells C. Western blotting analysis showed that two p62/IMP2-transfected clones (clone $6 \&$ clone 8) of MDA-MB-231 cells and two p62/IMP2-transfected clones (clone 16 \& clone 9) of LM2-4 cells strongly expressed the p62/IMP2 protein. These clones were chosen as p62/IMP2 positive clones. Two empty vectortransfected clones (clone 5 for MDA-MB-231 cells and clone 11 for LM2-4 cells), that do not express p62/IMP2 protein, were chosen as p62/IMP2 negative clones. D. Immunofluorescence staining of p62/IMP2 in MDA-MB-231 cells and LM2-4 cells. There was no p62/IMP2 staining in the negative clones and in the parental cells. In the positive clones, the staining of p62/IMP2 (green) was mainly localized to the cytoplasm. Cell nucleuses were stained with DAPI (blue). 
A

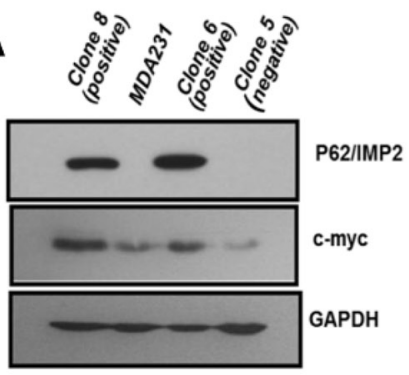

B

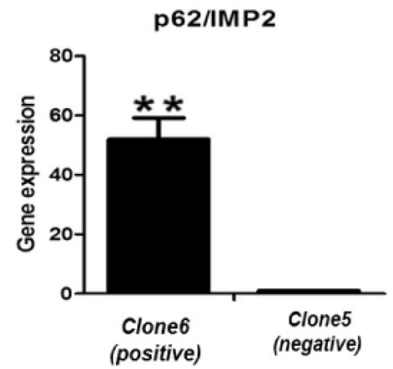

C

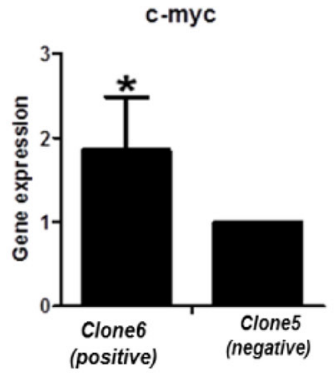

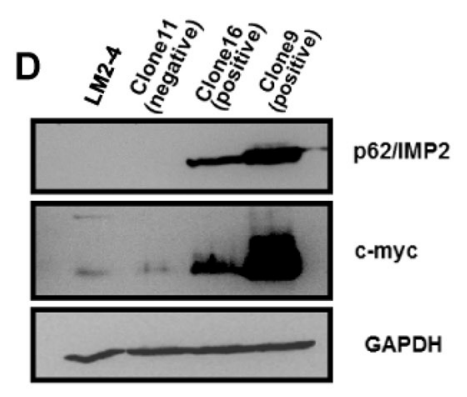
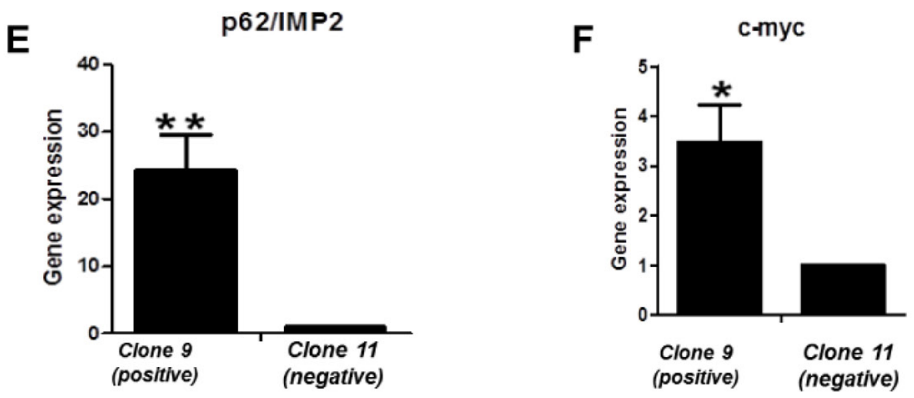

Figure 4: Expression of c-myc protein is increased with the overexpression of p62/IMP2. Increased c-myc protein was detected by Western blotting in MDA-MB-231 cells A. and LM2-4 cells D. transfected with p62/IMP2. The increased c-myc in mRNA level was detected by real-time PCR in MDA-MB-231 cells B, C. and LM2-4 cells E, F. that transfected with p62/IMP2. A $t$-test was applied to analyze the results. ${ }^{*} p<0.05$ when compared with the negative clones. ${ }^{*} p<0.01$ when compared with negative clones. Values represent averages $\pm \mathrm{SEM}$ of three independent measurements.
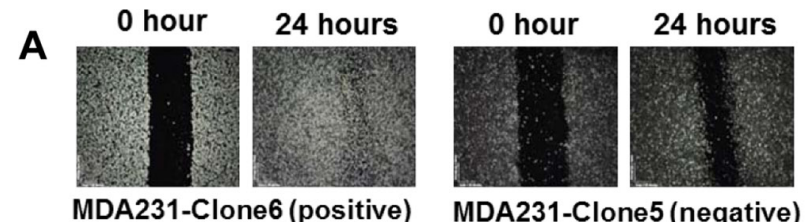

MDA231-Clone5 (negative)

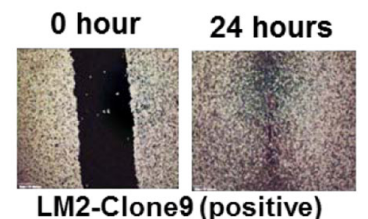

LM2-Clone9 (positive)

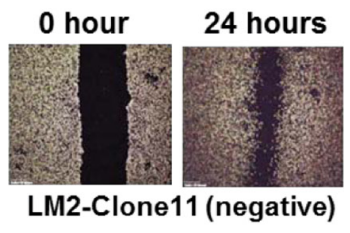

LM2-Clone11 (negative)
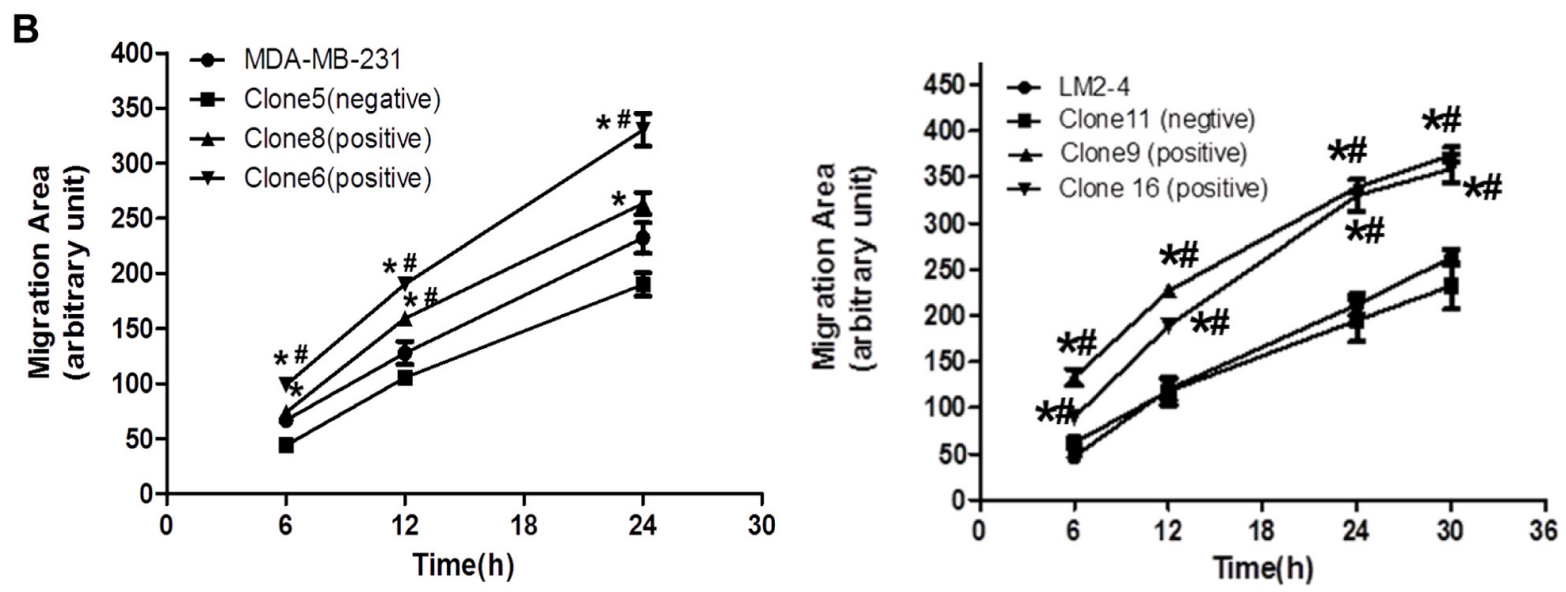

Figure 5: The impact of p62/IMP2 on breast cancer cells. Overexpression of p62/IMP2 can increase cell migration of MDAMB-231 cells and LM2-4 cells. Wound scratch images of p62/IMP2 positive/negative clones at different time points A. The level of cell migration into the wound scratch was quantified as migration area at each time point B. (Continued) 


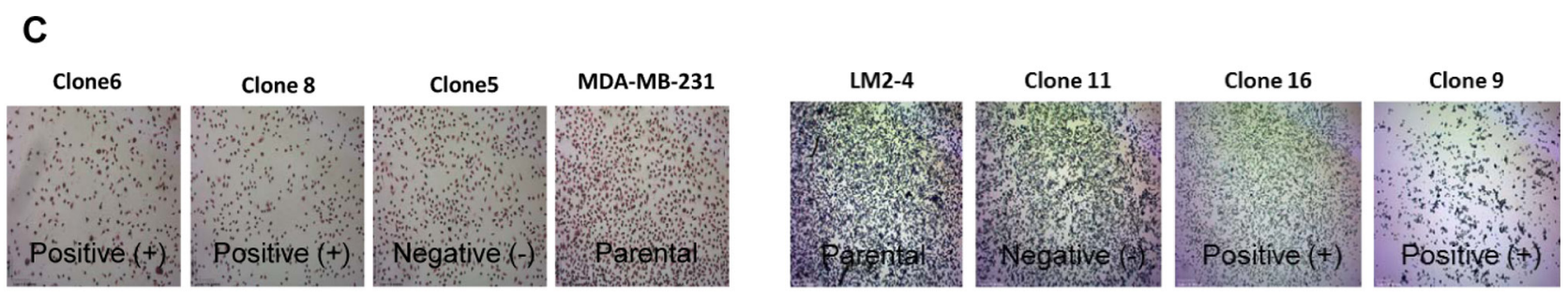

D
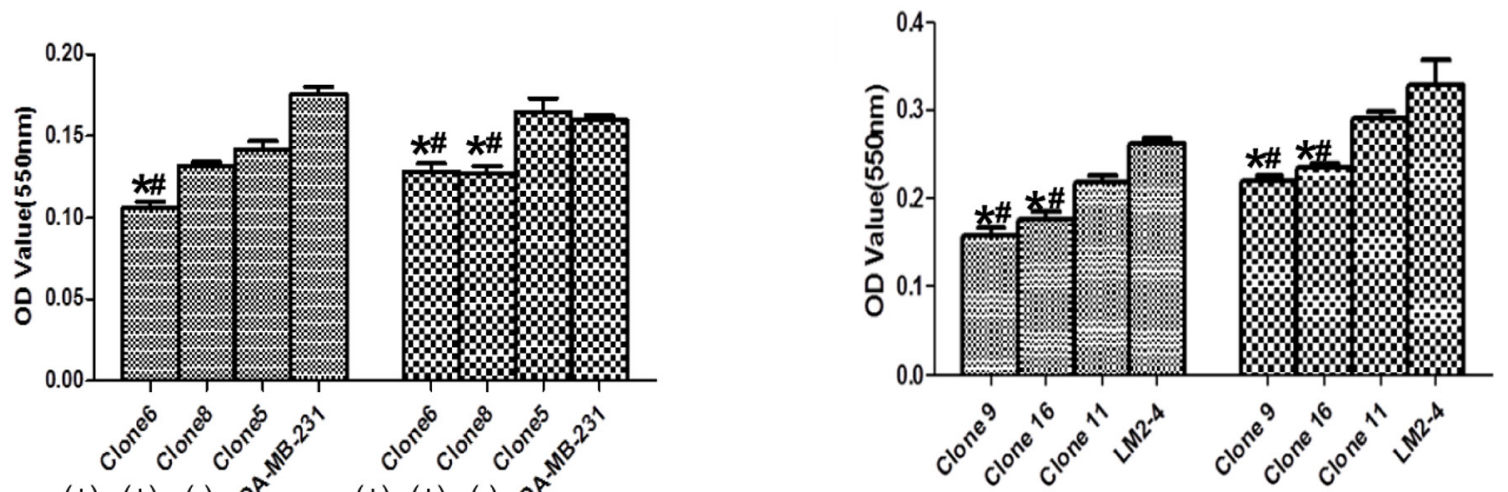

E

$(+) \quad(+) \quad(-)$ sis

$(+) \quad(+) \quad(-)$

$(+)(+) \quad(-)$
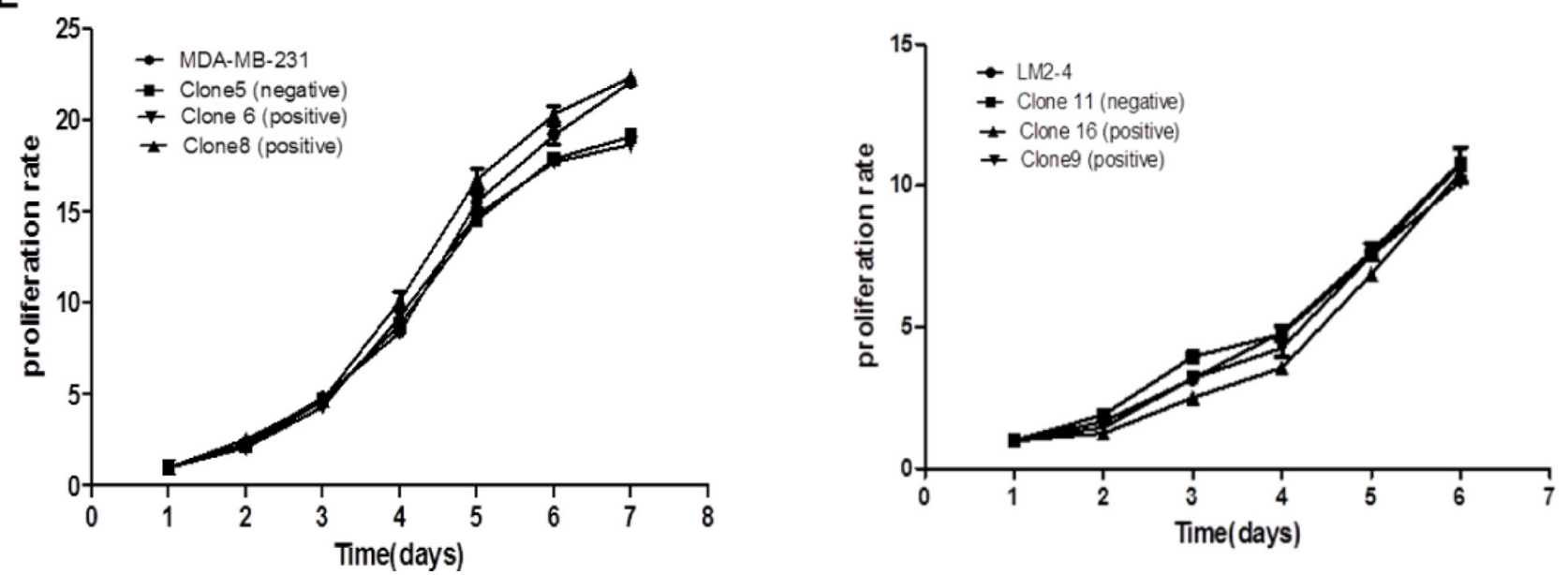

Figure 5: (Continued) The impact of p62/IMP2 on breast cancer cells. Overexpression of p62/IMP2 can reduce cell adhesion of MDA-MB-231 cells and LM2 cells. Crystal violet staining images of those p62/IMP2 positive/negative cells that attached at the bottom of collagen coated-wells $\mathbf{C}$. The number of attached cells from different cell lines was presented as optical density values following the staining D. Growth curve of p62/IMP2 positive/negative cells were compared, and there were no significant changes between groups E. A One-way ANOVA was applied to analyze the results. ${ }^{*} p<0.05$ when compared with negative clones. ${ }^{\#} p<0.05$ when compared with parental cells. Values represent averages \pm SEM of three independent measurements.

role of p62/IMP2 in various human tumor types. Anti-TAA autoantibodies are stable and can readily be detected by using ELISA, which can make these autoantibodies as potential markers of diseases. And number of anti-TAA autoantibodies have been reported to be present in sera from cancer patients [21]. Furthermore, the elevation of anti-TAA autoantibody levels also correlates with the occurrence of some cancers, so the detection of the anti-TAA autoantibody can be used for the immunodiagnosis of some types of cancer $[9,11]$.

Furthermore, using p62/IMP2 transfected cells, we observed that p62/IMP2 can increase cell migration and reduce cell adhesion to the extracellular matrix. Since increased cell migration and reduced cell adhesion are important in the process of tumor cell invasion, and tumor 
spread [22, 23], our results suggest some mechanism by which p62/IMP2 overexpression may contribute to breast cancer progression. To uncover the mechanisms by which p62/IMP2 regulates cell migration and cell adhesion, a Human Extracellular Matrix \& Adhesion Molecules RT ${ }^{2}$ Profiler PCR Array was carried out to observe mRNA changes regulated by $\mathrm{p} 62 / \mathrm{IMP} 2$. We found that most of genes with altered expression were up-regulated by overexpression of p62/IMP2. Our possible explanation is that, in p62/IMP2 overexprssing cells, these mRNAs are stabilized by binding to the p62/IMP2 protein. Among these genes, CTGF mRNA which has a short half-life was chosen to test such a possibility. Our results indicated that CTGF mRNA is a target of p62/IMP2, as shown by the mRNA half-life assay and RIP assay. The functional features of CTGF are very similar to p62/IMP2. CTGF plays important roles in many biological processes, including cell migration and adhesion, tissue development and stem cell pluripotency $[18,24]$. CTGF is also shown involved in some human disorders, such as diabetes, and some types of cancer. Several studies showed that the upregulation of CTGF correlates with cancer progression and metastasis such as in osteolytic metastasis of breast cancer $[25,26]$. CTGF has been reported to promote tumor metastasis by increasing matrix metalloproteinase expression [27]. In a recent study, CTGF was shown to be up-regulated in p62/IMP2 transgenic mice and the upregulated expression of CTGF is TGF-beta-independent
[28]. This study also suggested that IL13 might be involved in its up-regulation. In that respect, our data showed that p62/IMP2 can bind to mRNA of CTGF directly and stabilize its mRNA.

How p62/IMP2 regulates other genes (such as ADAMTS1, VCAN and COL7A1) remains unknown. ADAMTS1 is necessary for normal growth, and ADAMTS1 null mice were observed to exhibit growth retardation $[29,30]$. Versican is well-known as an anti-adhesive molecule, which has been reported to reduce the attachment of prostate cancer cells and melanoma to fibronectin-coated surfaces in vitro [31]. Therefore p62/IMP2 interacts with a number of genes associated with cell adhesion.

In summary, we observed that p62/IMP2 is highly expressed in breast cancer tissues. We also found that the overexpression of p62/IMP2 can regulate the mRNAs for extracellular matrix and adhesion molecules such as CTGF, ADAMTS1, COL7A1, and VCAN. These changes could contribute to the observed increased cell migration and reduced cell adhesion, which can contribute to an increased malignant behavior of breast cancer cells.

\section{MATERIALS AND METHODS}

\section{Tissue and sera collection}

For the analysis of breast cancer tissues and control tissues, formalin-fixed, paraffin-embedded, breast tissue

\section{A}

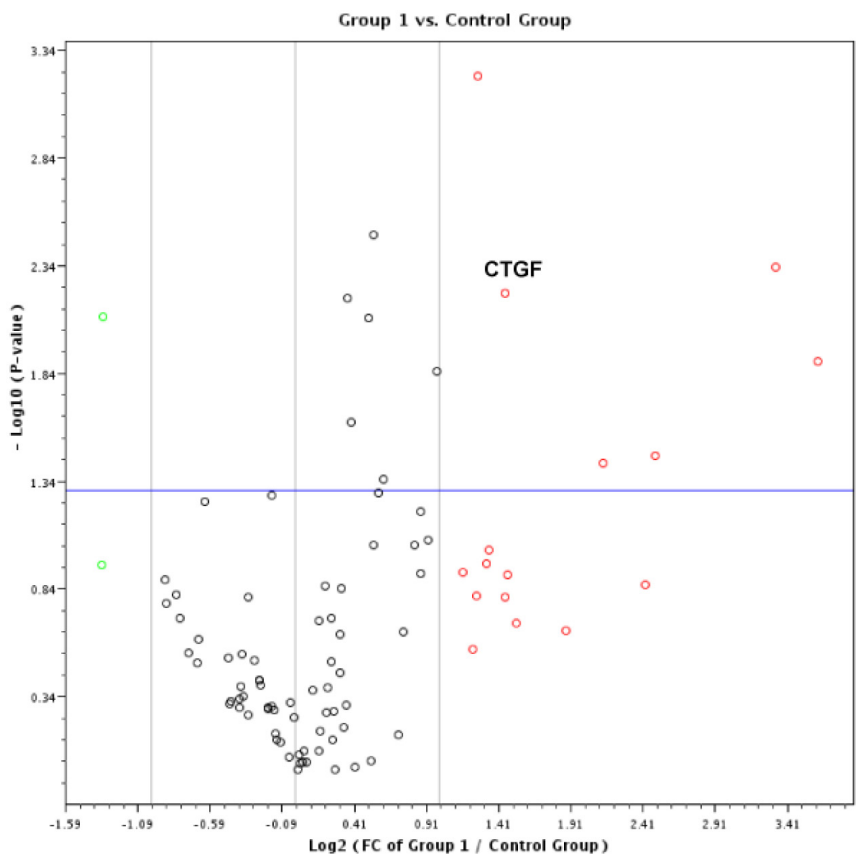

Figure 6: Changes in genes expression associated with p62/IMP2 overexpression. A volcano plot for the relative gene expression from MDA-MB-231 cells with overexpression of p62/IMP2, using Human Extracellular Matrix \& Adhesion Molecules RT2 Profiler PCR Array A. Down-regulated genes are highlighted as green, and up-regulated genes in red (Fold difference: 2). Gene expression above the horizontal line indicated that $p$-value less than, or equal to, 0.05. Group 1: clone 6 (p62/IMP2+) \& Control Group: clone 5 (p62/IMP2-). (Continued) 
B
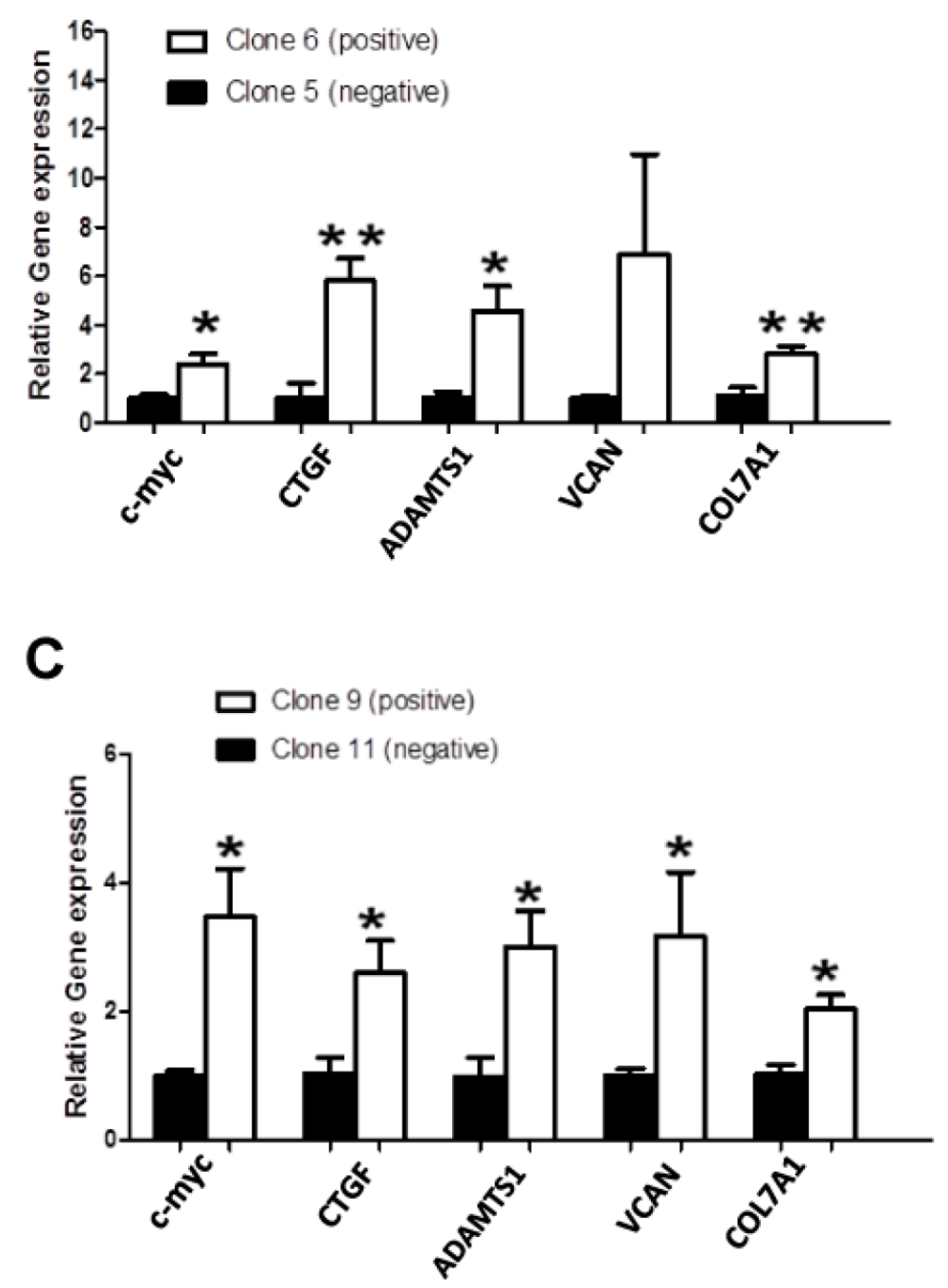

Figure 6: (Continued) Changes in genes expression associated with p62/IMP2 overexpression. Increased mRNA of versican, CTGF, ADAMTS1, and COL7A1 were confirmed again with our primers in MDA-MB-231 cells. B. and LM2-4 cells C. qPCR data were normalized to the housekeeping gene, GAPDH. A $t$-test was applied to analyze the results. ${ }^{*} p<0.05$ when compared with the negative clones. ${ }^{*} p<0.01$ when compared with negative clones. Values represent averages $\pm \mathrm{SEM}$ of three independent measurements.

Table 3: The changed genes encoding extracellular matrix and adhesion molecules with stable overexpression of p62/IMP2 in MDA-MB-231 cells (also confirmed in LM2-4 cells)

\begin{tabular}{l|l|c|c|l|}
\hline \multicolumn{2}{c}{ Gene } & \multicolumn{1}{c}{$\begin{array}{c}\text { Fold } \\
\text { Regulation }\end{array}$} & GenBank & \multicolumn{1}{c}{ Function } \\
\hline VCAN & Versican & 12.3084 & NM_004385 & $\begin{array}{l}\text { An anti-adhesive } \\
\text { molecule }\end{array}$ \\
\hline CTGF & Connective tissue growth factor & 2.735 & NM_001901 & Tissue wound repair \\
\hline ADAMTS1 & $\begin{array}{l}\text { ADAM metallopeptidase with } \\
\text { thrombospondin type 1 motif, } 1\end{array}$ & 4.3815 & NM_006988 & $\begin{array}{l}\text { Tumor growth and } \\
\text { metastasis }\end{array}$ \\
\hline COL7AL & Collagen, type VII, alpha1 & 2.5052 & NM_000094 & $\begin{array}{l}\text { Interaction with } \\
\text { laminin and fibronectin }\end{array}$ \\
\hline
\end{tabular}


A

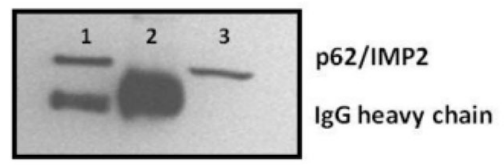

C

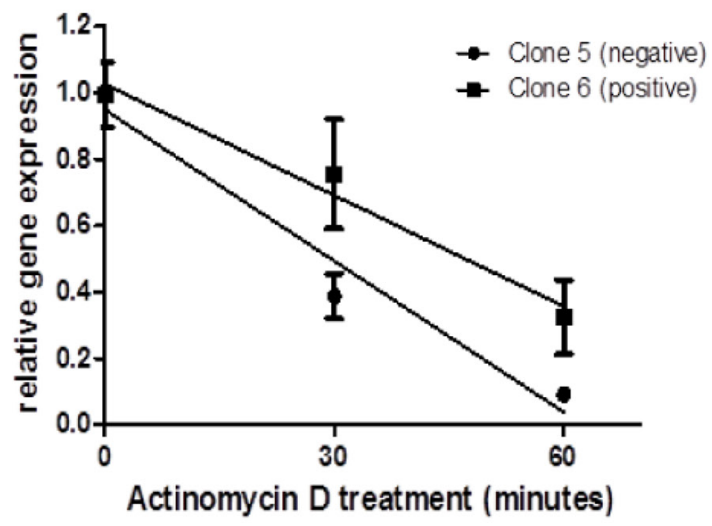

B

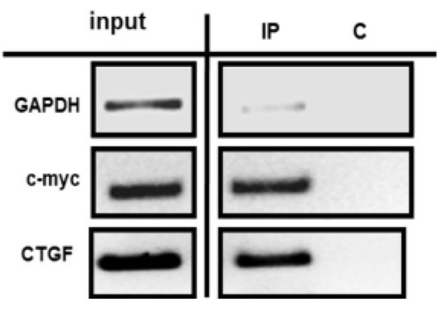

D

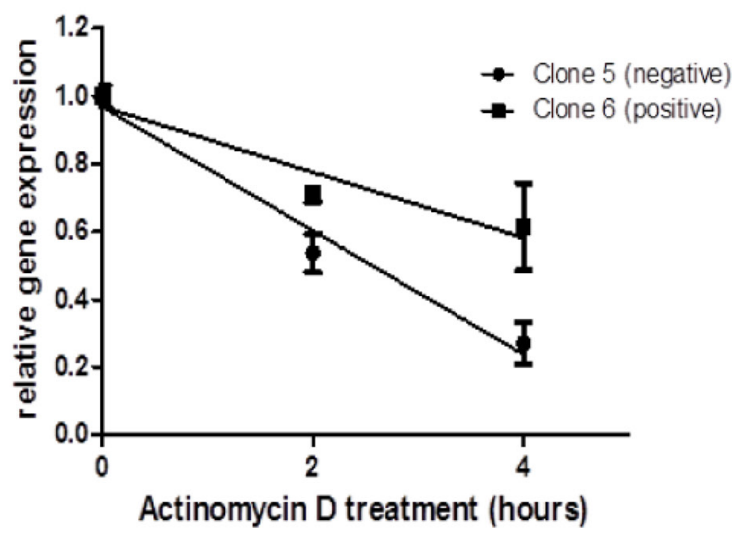

Figure 7: CTGF mRNA is a novel target of p62/IMP2. RIP assay was performed in MDA-MB-231 cells with overexpression of p62/IMP2 A \& B. (A) p62/IMP2 expression level was analyzed by western blotting. Lane1: post-IP beads of anti-p62/IMP2 antibody. Lane2: post-IP beads of Normal mouse IgG. Lane3: input sample. (B) p62/IMP2 binds to mRNAs of CTGF and c-myc but not GAPDH. C. p62/IMP2 regulates the stability of c-myc mRNA. D. p62/IMP2 regulates stability of CTGF mRNA.

arrays were purchased from US Biomax, Inc (MD, USA). These included (as described by US Biomax) 54 cases of breast invasive ductal carcinoma, 40 cases of lymph node metastasis, 10 cases of other types of breast cancer tissue, and 14 cases of adjacent normal tissue. A total of 323 human sera were analyzed, and they were obtained from the serum bank of The Cancer Autoimmunity and Epidemiology Research Laboratory at UTEP (University of Texas at El Paso). These samples were originally provided to us by our clinical collaborators. Among them, 216 serum samples were from patients diagnosed with breast cancer (70 samples from Germany, 104 samples from China, 42 samples from Mexico), 34 sera were from individuals with begin breast lumps, and 73 sera were from individuals with no evidence of malignancy. None of the patients with breast cancer received any chemotherapy or radiotherapy at the time whenthe sera were collected. All serum samples were collected from consenting individuals.

\section{Cell culture and transfection}

MDA-MB-231 and LM2-4 cell lines were cultured in Dulbecco's Modified Eagle Medium (GIBCO, Life Techologies, Grand Island, NY, USA) with $10 \%$ fetal bovine serum (GIBCO, Life Technologies, Grand Island,
NY, USA) and 100 units $/ \mathrm{ml}$ penicillin plus $100 \mu \mathrm{g} / \mathrm{ml}$ streptomycin at $37^{\circ} \mathrm{C}$ with $10 \% \mathrm{CO} 2$. Cells were plated in 6-well plates and transfected with Lipofectamine 2000 (Life Techologies, Grand Island, NY, USA). We used a p62-pcDNA3.1 plasmid to transfect MDA-MB-231 and LM2-4 cells, and pcDNA3.1 (empty vector) was used to generate control transfectants. Variants with stable overexpression of p62/IMP2 were selected in DMEM medium containing $1 \mathrm{mg} / \mathrm{ml}$ G418.

\section{Enzyme-linked immunosorbent assay (ELISA)}

ELISA was performed as described in our previous study [32]. In brief, polystyrene 96-wells microtiter plates (Thermo scientific, Waltham, MA, USA) were coated overnight at $4{ }^{\circ} \mathrm{C}$ with purified recombinant p62/IMP2 $(0.5 \mu \mathrm{g} / \mathrm{ml})$ in phosphate-buffered saline (PBS), and then blocked with post-coating solution. Antigen-coated wells were incubated with $100 \mu \mathrm{l}$ human sera, diluted at 1:100, for 2 hours. The antigen-antibody complex were further bound to HRP-conjugated goat anti-human IgG (Santa Cruz Biotechonolgy, Inc., Santa Cruz, CA, USA) and detected by the substrate 2,2'-azino-bis-3-ethylbenzo-thiazoline-6sulfonic acid (ABTS: Sigma-Aldrich, St. Louis, MO, USA). Optical density (OD) was measured at $405 \mathrm{~nm}$. 


\section{Immunohistochemistry and immunofluorescence}

Immunohistochemistry was performed using standard protocols. We used anti-p62/IMP2 antibody as primary antibody, and polyvalent biotinylated link was used as secondary antibody. DAB reagent was used for detection of p62/IMP2. For immunofluorescence, cells were seeded into 8-chamber culture slides. The cells were treated with p62/IMP2 antibody, and incubated with Alexa Flour 488 conjugate. Mounting medium containing DAPI was then added. Confocal fluorescence images were acquired with a laser scanning microscope (LSM 700; Zeiss, New York, NY, USA).

\section{In vitro wound healing assay}

Cells were seeded in 6-well plates and cultured in DMEM medium with 2\% FBS. A wound scratch was created using a sterile $1 \mathrm{ml}$ pipette tip. Scratch images of the wounds were photographed every 6 hours. The migration area of cells into the wound was quantified at each time point with Image $\mathrm{J}$ software.

\section{In vitro cell-extracellular matrix adhesion assay}

96-well plates were coated with $10 \mu \mathrm{g} / \mathrm{ml}$ fibronectin or $10 \mu \mathrm{g} / \mathrm{ml}$ type I collagen, and incubated overnight at $4^{\circ} \mathrm{C}$. Non-specific binding sites were blocked with $1 \%$ BSA in serum-free culture medium. Cells $\left(5 \times 10^{3}\right)$ were cultured in the coated wells and incubated at $37^{\circ} \mathrm{C}$ for 1 to 2 hours. Then non-adherent cells were removed by washing with washing buffer $(0.5 \%$ BSA in serum-free culture medium). Attached cells were stained with crystal violet $(5 \mathrm{mg} / \mathrm{ml}$ in $20 \%$ ethanol). Optical density was measured at $550 \mathrm{~nm}$.

\section{Cell proliferation assay}

Cells $\left(5 \times 10^{3}\right)$ were seeded on to 96 -well plates, grown for 1 to 7 days. The growth of cells was determined by the sulforhodamine (SRB) assay. Briefly, the cells were fixed with $10 \%$ trichloracetic acid (TCA) for 1 hour at $4^{\circ} \mathrm{C}$, rinsed five times with water, and air dried. Fixed cells were stained with $0.4 \%$ SRB in acetic acid. Unbound dye was removed by washing 5 times with $1 \%$ acetic acid, and plates were air dried. The staining was solubilized with $10 \mathrm{Mm}$ Tris Base. The colorimetric reading was carried out in a microplate autoreader set at $515 \mathrm{~nm}$.

\section{RNA isolation and quantitative real-time RT-PCR}

Total RNA from breast cancer cells was isolated by AllPrep DNA/RNA/Protein Mini Kit (QIAGEN, Valencia, CA, USA). RNA integrity was assessed by $0.7 \%$ agarose gel electrophoresis. RNA was reversely transcribed with GoScriptTM Reverse Tanscription System. The following primers were used: c-myc forward, 5'-AG CGACTCTGAGGAGGAAC-3' and reverse, 5'-CGT
AGTTGTGCTGATGTGTG-3'; CTGF forward, 5'-CACAG AGTGGAGCGCCTGTTC- $3^{\prime}$ and reverse, 5'- GATGCA CTTTTTGCCCTTCTTAATG-3'; ADAMTS1 forward, 5'-TG

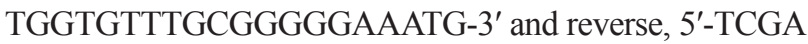
TGTTGGTGGCTCCAGTT-3'; COL7A1 forward, 5'-GGC TGCAATTCTCCATGTGG-3' and reverse, 5'-CTGTGA GGCAACTCGCTTCA-3'; VCAN forward, 5'-TCACTCT AATCCCTGTCGTAATG-3' and reverse, 5'-ATGTCTCGG TATCTTGCTCAC-3'; p62/IMP2 forward, 5'-AGTGGAAT TGCATGGGAAAATCA-3' and reverse, 5'-CAACGGCG GTTTCTGTGTC-3'; GAPDH forward, 5'-GAAGGTG AAGGTCGGAGTC-3' and reverse, 5'- GAAGATGGTG ATGGGATTTC-3'. Real-time PCR was performed with MyiQ Single Color Real-time PCR Detection System, as was the RT Profiler PCR Array kit.

\section{RNA immunoprecipitation}

p62/IMP2-bound RIP was performed according to the RiboCluster Profiler RIP-Assay Kit (Medical \& Biological Laboratories CO., LTD. Japan). Briefly, cell lysates were collected from p62/IMP2 positive cells, and then the whole complexes of p62/IMP2-targets from cell lysate were pulled down with p62/IMP2 antibody. The target mRNAs were separated and isolated for subsequent reverse transcription.

\section{mRNA half-life analysis}

Cells $\left(1 \times 10^{6}\right)$ seeded in to 6-well plates were treated with $5 \mathrm{ug} / \mathrm{ml}$ actinomycin D (Sigma, St. Louis, MO, USA), and then these cells were collected every 30 minutes or 2 hours. Total RNA was isolated from collected cells. The amount of GAPDH, c-myc and CTGF mRNAs was quantified by Real-Time RT-PCR.

\section{Statistical analysis}

The mean OD value of the group of patients' sera was compared using the Mann-Whitney $U$ test. The frequency of antibody against p62/IMP2 in the sera from groups was compared using $X^{2}$ test. The p62/IMP2 expression in breast tissues was analyzed by $X^{2}$ test and Fisher's text. A one-way ANOVA was applied to analyze results from wound healing assay, adhesion assay, and proliferation assay. The mRNA half-life was calculated from the first-order decay constants (K) obtained with the PRISM software program, version 3.03 (GraphPad, San Diego, CA): half-life $=\ln 2 / \mathrm{k}$. Comparisons between half-life of mRNAs were performed with the $t$-test. Data were presented as means \pm SEM of three independent experiments. $p<0.05$ was considered statistically significant.

\section{ACKNOWLEDGMENTS AND FUNDING}

Authors thanks Drs. Wei Qian, Jianjun Sun and Marc Cox at UTEP (The University of Texas at El Paso) for their support and help to this study. This work was 
supported by a grant (SC1CA166016) from the National Institutes of Health (NIH). We also thank the Border Biological research Center (BBRC) Core Facilities at The University of Texas at El Paso (UTEP) for their support, which were funded by NIH grant (5G12M007590).

\section{CONFLICTS OF INTEREST}

The authors declare that they have no conflict of interest.

\section{REFERENCES}

1. Christiansen J, Kolte AM, Hansen T, Nielsen FC. IGF2 mRNA-binding protein 2: biological function and putative role in type 2 diabetes. J Mol Endocrinol. 2009; 43:187-195.

2. Nielsen FC, Nielsen J, Christiansen J. A family of IGF-II mRNA binding proteins (IMP) involved in RNA trafficking. Scand J Clin Lab Invest Suppl. 2001; 234:93-99.

3. Bell JL, Wachter K, Muhleck B, Pazaitis N, Kohn M, Lederer M, Huttelmaier S. Insulin-like growth factor 2 mRNAbinding proteins (IGF2BPs): post-transcriptional drivers of cancer progression?. Cell Mol Life Sci. 2013; 70:2657-2675.

4. Janiszewska M, Suva ML, Riggi N, Houtkooper RH, Auwerx J, Clement-Schatlo V, Radovanovic I, Rheinbay E, Provero P, Stamenkovic I. Imp2 controls oxidative phosphorylation and is crucial for preserving glioblastoma cancer stem cells. Genes Dev. 2012; 26:1926-1944.

5. Cleynen I, Brants JR, Peeters K, Deckers R, DebiecRychter M, Sciot R, Van de Ven WJ, Petit MM. HMGA2 regulates transcription of the Imp2 gene via an intronic regulatory element in cooperation with nuclear factor-kappaB. Mol Cancer Res. 2007; 5:363-372.

6. Li Z, Zhang Y, Ramanujan K, Ma Y, Kirsch DG, Glass DJ. Oncogenic NRAS, required for pathogenesis of embryonic rhabdomyosarcoma, relies upon the HMGA2-IGF2BP2 pathway. Cancer research. 2013; 73:3041-3050.

7. Li Z, Gilbert JA, Zhang Y, Zhang M, Qiu Q, Ramanujan K, Shavlakadze T, Eash JK, Scaramozza A, Goddeeris MM, Kirsch DG, Campbell KP, Brack AS, Glass DJ. An HMGA2-IGF2BP2 axis regulates myoblast proliferation and myogenesis. Developmental cell. 2012; 23:1176-1188

8. Boudoukha S, Cuvellier S, Polesskaya A. Role of the RNAbinding protein IMP-2 in muscle cell motility. Molecular and cellular biology. 2010; 30:5710-5725.

9. Zhang JY, Chan EK, Peng XX, Tan EM. A novel cytoplasmic protein with RNA-binding motifs is an autoantigen in human hepatocellular carcinoma. J Exp Med. 1999; 189:1101-1110.

10. Liu W, Li Z, Xu W, Wang Q, Yang S. Humoral autoimmune response to IGF2 mRNA-binding protein (IMP2/p62) and its tissue-specific expression in colon cancer. Scand J Immunol. 2013; 77:255-260.
11. Casiano CA, Mediavilla-Varela M, Tan EM. Tumorassociated antigen arrays for the serological diagnosis of cancer. Mol Cell Proteomics. 2006; 5:1745-1759.

12. Liu X, Ye H, Li L, Li W, Zhang Y, Zhang JY. Humoral autoimmune responses to insulin-like growth factor II mRNA-binding proteins IMP1 and p62/IMP2 in ovarian cancer. J Immunol Res. 2014; 2014:326593.

13. Lu M, Nakamura RM, Dent ED, Zhang JY, Nielsen FC, Christiansen J, Chan EK, Tan EM. Aberrant expression of fetal RNA-binding protein p62 in liver cancer and liver cirrhosis. The American journal of pathology. 2001; 159:945-953.

14. Zhang L, Liu Y, Hao S, Woda BA, Lu D. IMP2 expression distinguishes endometrioid from serous endometrial adenocarcinomas. The American journal of surgical pathology. 2011; 35:868-872.

15. Zhang J, Chan EK. Autoantibodies to IGF-II mRNA binding protein p62 and overexpression of p62 in human hepatocellular carcinoma. Autoimmunity reviews. 2002; $1: 146-153$.

16. Doyle GA, Bourdeau-Heller JM, Coulthard S, Meisner LF, Ross J. Amplification in human breast cancer of a gene encoding a c-myc mRNA-binding protein. Cancer research. 2000; 60:2756-2759.

17. Tessier CR, Doyle GA, Clark BA, Pitot HC, Ross J. Mammary tumor induction in transgenic mice expressing an RNA-binding protein. Cancer research. 2004; 64:209-214.

18. Aguiar DP, de Farias GC, de Sousa EB, de Mattos Coelho-Aguiar J, Lobo JC, Casado PL, Duarte ME, Abreu JG Jr. New strategy to control cell migration and metastasis regulated by CCN2/CTGF. Cancer cell international. 2014; $14: 61$.

19. Kubota S, Takigawa M. Cellular and molecular actions of $\mathrm{CCN} 2 / \mathrm{CTGF}$ and its role under physiological and pathological conditions. Clinical science. 2015; 128:181-196.

20. Su Y, Qian H, Zhang J, Wang S, Shi P, Peng X. The diversity expression of p62 in digestive system cancers. Clin Immunol. 2005; 116:118-123.

21. Tan HT, Low J, Lim SG, Chung MC. Serum autoantibodies as biomarkers for early cancer detection. The FEBS journal. 2009; 276:6880-6904.

22. Cai X, Luo J, Yang X, Deng H, Zhang J, Li S, Wei H, Yang C, Xu L, Jin R, Li Z, Zhou W, Ding J, Chu J, Jia L, Jia Q, et al. In vivo selection for spine-derived highly metastatic lung cancer cells is associated with increased migration, inflammation and decreased adhesion. Oncotarget. 2015; 6:22905-22917.

23. Gui GP, Puddefoot JR, Vinson GP, Wells CA, Carpenter R. Altered cell-matrix contact: a prerequisite for breast cancer metastasis? Br J Cancer. 1997; 75:623-633.

24. Chang $\mathrm{CC}$, Hsu WH, Wang $\mathrm{CC}$, Chou CH, Kuo MY, Lin BR, Chen ST, Tai SK, Kuo ML, Yang MH. Connective tissue growth factor activates pluripotency genes and mesenchymal-epithelial transition in head and neck cancer cells. Cancer research. 2013; 73:4147-4157. 
25. Chang CC, Shih JY, Jeng YM, Su JL, Lin BZ, Chen ST, Chau YP, Yang PC, Kuo ML. Connective tissue growth factor and its role in lung adenocarcinoma invasion and metastasis. Journal of the National Cancer Institute. 2004; 96:364-375.

26. Shimo T, Kubota S, Yoshioka N, Ibaragi S, Isowa S, Eguchi T, Sasaki A, Takigawa M. Pathogenic role of connective tissue growth factor (CTGF/CCN2) in osteolytic metastasis of breast cancer. Journal of bone and mineral research : the official journal of the American Society for Bone and Mineral Research. 2006; 21:1045-1059.

27. Tsai HC, Su HL, Huang CY, Fong YC, Hsu CJ, Tang CH. CTGF increases matrix metalloproteinases expression and subsequently promotes tumor metastasis in human osteosarcoma through down-regulating miR-19d. Oncotarget. 2014; 5:3800-3812.

28. Simon Y, Kessler SM, Bohle RM, Haybaeck J, Kiemer AK. The insulin-like growth factor 2 (IGF2) mRNA-binding protein p62/IGF2BP2-2 as a promoter of NAFLD and HCC? Gut. 2014; 63:861-863.
29. Shindo T, Kurihara H, Kuno K, Yokoyama H, Wada T, Kurihara Y, Imai T, Wang Y, Ogata M, Nishimatsu H, Moriyama N, Oh-hashi Y, Morita H, Ishikawa T, Nagai R, Yazaki Y, et al. ADAMTS-1: a metalloproteinase-disintegrin essential for normal growth, fertility, and organ morphology and function. The Journal of clinical investigation. 2000; 105:1345-1352.

30. Mittaz L, Russell DL, Wilson T, Brasted M, Tkalcevic J, Salamonsen LA, Hertzog PJ, Pritchard MA. Adamts-1 is essential for the development and function of the urogenital system. Biology of reproduction. 2004; 70 : 1096-1105.

31. Sakko AJ, Ricciardelli C, Mayne K, Suwiwat S, LeBaron RG, Marshall VR, Tilley WD, Horsfall DJ. Modulation of prostate cancer cell attachment to matrix by versican. Cancer research. 2003; 63:4786-4791.

32. Zhu Q, Han SX, Zhou CY, Cai MJ, Dai LP, Zhang JY. Autoimmune response to PARP and BRCA1/BRCA2 in cancer. Oncotarget. 2015; 6:11575-11584. 